\title{
Quality of life following hip fractures: results from the Norwegian hip fracture register
}

\author{
Jan-Erik Gjertsen ${ }^{1,2^{*}}$, Valborg Baste ${ }^{1}$, Jonas M. Fevang ${ }^{1}$, Ove Furnes ${ }^{1,2}$ and Lars Birger Engesæter ${ }^{1,2}$
}

\begin{abstract}
Background: Patient-reported health-related quality of life is an important outcome measure when assessing the quality of hip fracture surgery. The frequently used EQ-5D index score has unfortunately important limitations. One alternative can be to assess the distribution of each of the five dimensions of the patients' descriptive health profile. The objective of this paper was to investigate health-related quality of life (HRQoL) after hip fractures.

Methods: Data from hip fracture operations from 2005 through 2012 were obtained from The Norwegian Hip Fracture Register. Patient reported HRQoL, (EQ-5D-3L) was collected from patients preoperatively and at four and twelve months postoperatively $n=10325$. At each follow-up the distribution of the EQ-5D-3L and mean pain VAS was calculated.

Results: Generally, a higher proportion of patients reported problems in all 5 dimensions of the EQ-5D-3L at all follow-ups compared to preoperative. Also a high proportion of patients with no preoperative problems reported problems after surgery; At 4 and 12 months follow-ups $71 \%$ and $58 \%$ of the patients reported walking problems, and $65 \%$ and $59 \%$ of the patients reported pain respectively. Patients with femoral neck fractures and the youngest patients (age < 70 years) reported least problems both preoperatively and at all follow-ups.

Conclusions: A hip fracture has a dramatic impact on the patients' HRQoL, and the deterioration in HRQoL sustained also one year after the fracture. Separate use of the descriptive profile of the EQ-5D is informative when assessing quality of life after hip fracture surgery.
\end{abstract}

Keywords: Health related quality of life, Hip fractures, Orthopaedic surgery, Femoral neck fractures, National results

\section{Background}

Osteosynthesis of hip fractures, and in particular the displaced fractures of the femoral neck (FFN), has been associated with a high risk of reoperations [1-5]. In the later years, however, there has been a trend towards primary arthroplasty for the displaced FFNs $[6,7]$ and accordingly the number of reoperations for these specific fractures has decreased [6]. Nevertheless, for the individual patients any major reoperation represents a temporary increase in both morbidity and mortality. The number of reoperations has traditionally been the most common way of reporting the outcome after hip fracture

\footnotetext{
* Correspondence: jan-erik.gjertsen@helse-bergen.no

${ }^{1}$ Department of Orthopaedic Surgery, Haukeland University Hospital, Jonas Lies vei 65, N 5021 Bergen, Norway

${ }^{2}$ Department of Clinical Medicine, Faculty of Medicine and Odontology, University of Bergen, Bergen, Norway
}

surgery. The recent decades, however, an increasing number of studies on hip fractures have focused also on other outcome variables, such as functional outcome and patient-reported outcome measures (PROM) [1, 3, 8-10]. The importance of such PROM data when measuring the quality of surgery in orthopaedic studies has been advocated by several authors $[11,12]$.

It is well-known that a hip fracture has impact on patients' quality of life $[1,3,8,9,13-17]$. Most studies that have used the EQ-5D-3L as an instrument for measuring quality of life have used the EQ-5D index score, which is a weighted value that can be calculated from different tariffs with adjustments for cultural and national differences. Several studies have lately reported important limitations of this index score, such as bimodal or trimodal distribution and a ceiling effect [18-20]. One other 
disadvantage of the EQ-5D index-score is that this single value does not provide information on in which way the patients' quality of life is reduced. To get as much information as possible from the EQ-5D data one alternative can be to investigate and report separately the distribution of each of the five dimensions of health-related quality of life; mobility, self-care, usual activities, pain/ discomfort, and anxiety/depression, as presented in this study.

The Norwegian Hip Fracture Register (NHFR) has recorded hip fractures on a national level since 2005 [21]. Besides data on reoperations and mortality, the NHFR also provides PROM data including the EQ-5D$3 \mathrm{~L}$ questionnaire. Based on data from the NHFR we aimed to investigate the changes in quality of life associated with hip fractures.

\section{Methods}

The NHFR collects data on hip fractures in Norway as a prospective observational study. Compared with the Norwegian Patient Registry, the completeness of the registration has earlier been found to be approximately $89 \%$ [6]. The Norwegian Data Inspectorate approved the recording of data. All patients signed an informed consent form that was entered into their hospital medical record. Data on each primary operation for hip fractures are reported on standard one-page forms to the register by the surgeon. The form includes information on the patients (age, sex, cognitive function, and ASA-class [22]), the fracture, and the operation. A more thoroughly description of the NHFR has been published earlier [21]. In the present study the fractures were categorized into three groups: intracapsular fractures of femoral neck (FFN), trochanteric fractures (including basocervical fractures), and subtrochanteric fractures (including AO/AAOS A3 "Intertrochanteric" fractures).

The patients received questionnaires directly from the register 4 and 12 months postoperatively. These questionnaires included the Norwegian translation of the Euroqol [23]. The Euroqol is a standardized non-disease-specific tool for describing the health-related quality of life. Both the health status part (EQ-5D-3L) and the visual analogue scale (EQ-VAS) were filled in by the patients. The EQ-5D$3 \mathrm{~L}$ is based on five dimensions of health-related quality of life; mobility, self-care, usual activities, pain/discomfort, and anxiety/depression. Each item has three levels of severity; no problems, some problems, or major problems. The EQ-5D data in this article are presented as health profiles from this descriptive system. The preoperative EQ-5D health profile was reported as part of the fourmonth questionnaire, and consequently retrospectively recorded by the patients. Furthermore, the questionnaires included a visual analogue scale (VAS 0-100) where the patients reported the average level of pain from the operated hip during the last months (with 0 indicating no pain and 100 indicating extreme pain).

\section{Study sample}

Patients operated due to an acute hip fracture and reported to the NHFR from 2005 to 2012 were eligible for inclusion in the present study. As of December 31, 2012 there were 63,231 hip fractures recorded in the NHFR. The four months questionnaire had been sent to 37,968 patients and the twelve months questionnaire had been

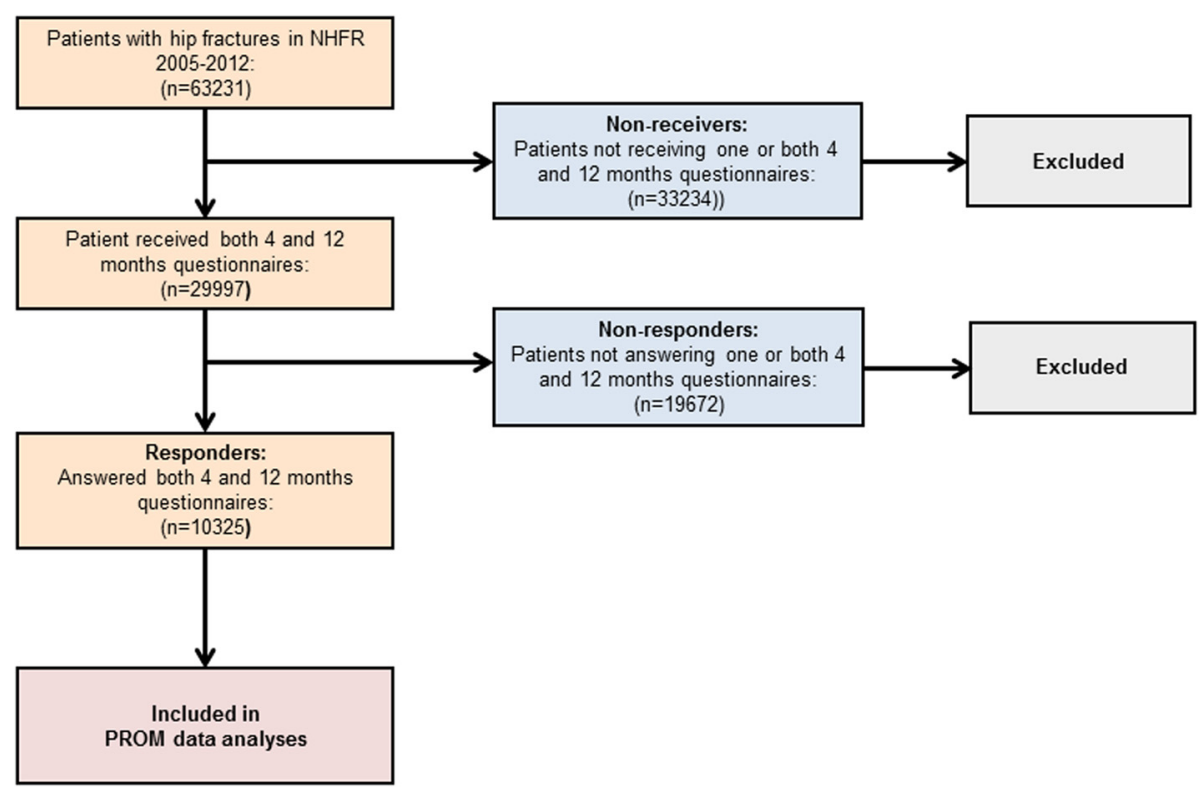

Fig. 1 Flow chart of patients included in the study 
sent to 30,400 patients. The response rates to the questionnaires were $54 \%$ at four months and $49 \%$ at twelve months. Only patients who had received and completely filled in both the four- and twelve months questionnaires were included in the study. Patients who died before time of the planned follow-up and patients with too short follow-up did not received questionnaires. Further, due to economical/administrative reasons only a randomly selected group of patients in the time period 2007-2009 received the questionnaires. A total of 29,997 patients received both questionnaires. Of these patients 10,324 (34 \%) answered both questionnaires completely, and were accordingly included in the study (Fig. 1).

The baseline characteristics for responders and nonresponders are presented in Table 1 . The responders were statistically significant younger, healthier according to the ASA classification, and less cognitively impaired compared to the non-responders. Further, there were small, but still statistically significant differences both in type of fracture and type of surgery (Table 1).

\section{Statistical analysis}

The results are presented as number and/or percent of patients reporting quality of life in each level of the five EQ-5D dimensions. The Pearson chi-squared test was used for comparison of categorical variables and the independent t-test was used for continuous variables. We performed sub-analyses for each of the five dimensions including only patients reporting no problems preoperatively. Further, separate analyses were done for different fracture types (FFN, trochanteric fracture, and subtrochanteric fracture) and for different age groups $(<70$ years, $70-80$ years, and $>80$ years). We did not adjust for patients who were operated on both sides. The significance level was set to 0.05 and all $p$ values were two-tailed. The statistical analyses were performed in the statistical package IBM SPSS statistics version 21 (SPSS Inc., Chicago, IL).

\section{Results}

\section{Quality of life}

Preoperatively, the majority of the patients reported no problems in each of the five dimensions of the EQ-5D (Table 2). Compared to their preoperative status, the proportion of patients reporting problems at four months more than doubled in the dimensions regarding mobility and self-care, and almost doubled regarding usual activities and pain/discomfort. At twelve months postoperatively there was still a marked increase of patients reporting problems in these dimensions compared to preoperatively. For the last dimension (Anxiety/depression) the changes were less evident.

When performing sub-analyses for each of the five EQ-5D dimensions including only patients with no
Table 1 Baseline characteristics for responders and nonresponders $^{a}$

\begin{tabular}{|c|c|c|c|}
\hline & $\begin{array}{l}\text { Responders } \\
(n=10325)\end{array}$ & $\begin{array}{l}\text { Non-responders } \\
(n=19672)\end{array}$ & $P$ value \\
\hline Mean age (yrs) (SD) & $77.3(11.7)$ & $79.8(11.7)$ & $<0.001^{*}$ \\
\hline Female (\%) & $7471(72.4)$ & $14420(73.3)$ & $0.097^{* *}$ \\
\hline ASA ${ }^{b}$-class (\%) & & & $<0.001^{* *}$ \\
\hline 1 & $1402(13.6)$ & $1420(7.2)$ & \\
\hline 2 & $4525(43.8)$ & $7262(36.9)$ & \\
\hline 3 & 3964 (38.4) & $9878(50.2)$ & \\
\hline 4 & $261(2.5)$ & $791(4.0)$ & \\
\hline 5 & $1(0)$ & $11(0.1)$ & \\
\hline Data missing & $172(1.7)$ & $310(1.6)$ & \\
\hline Cognitive impairment (\%) & & & $<0.001^{* *}$ \\
\hline No & $8267(80.1)$ & $12581(64.9)$ & \\
\hline Yes & $834(8.1)$ & $4290(22.1)$ & \\
\hline Uncertain & $659(6.4)$ & $2090(10.8)$ & \\
\hline Data missing & $565(5.5)$ & $431(2.2)$ & \\
\hline Fracture type (\%) & & & $<0.001^{* *}$ \\
\hline Femoral neck fracture & $5639(54.6)$ & $10236(52.0)$ & \\
\hline Trochanteric fracture & $3706(35.9)$ & 7635 (38.8) & \\
\hline Subtrochanteric fracture & $875(8.5)$ & $1586(8.1)$ & \\
\hline Other/missing & $105(1.0)$ & $215(1.1)$ & \\
\hline Primary operation (\%) & & & $<0.001^{* *}$ \\
\hline Screws/pins & $2643(25.6)$ & $4638(23.6)$ & \\
\hline Hemiarthroplasty & $2567(24.9)$ & $5161(26.2)$ & \\
\hline Total hip arthroplasty & $382(3.7)$ & $280(1.4)$ & \\
\hline Sliding hip screw & $3154(30.5)$ & $6466(32.9)$ & \\
\hline Intramedullary nail & $1249(12.1)$ & $2539(12.9)$ & \\
\hline Other & $330(3.2)$ & $588(3.0)$ & \\
\hline
\end{tabular}

a Responders: patients who completely answered both the 4 and 12 months questionnaires; Non reseponders: patients who received both the 4 and 12 months questionnaire but did not completely answered one or both questionnaires

${ }^{\mathrm{b}}$ ASA, American Society of Anaesthesiologists

*independent $t$-test

**Pearson chi-squared test

reported problems preoperatively, there was still a high proportion of patients reporting problems after four and twelve months (Table 3). In the group of patients reporting no problems in walking preoperatively $71 \%$ reported problems after 4 months and $58 \%$ had problems after 12 months postoperatively. Corresponding results were found for the ability of performing self-care and for usual activities where $29 \%$ and $53 \%$ respectively reported problems twelve months postoperatively. As much as $60 \%$ of the patients with no preoperative pain reported pain twelve months postoperative. 
Table 2 Descriptive profile of the 5 dimensions of EQ-5D after hip fracture. All patients included

\begin{tabular}{|c|c|c|c|}
\hline & $\begin{array}{l}\text { Preoperative } \\
n(\%)\end{array}$ & $\begin{array}{l}4 \text { months postop } \\
n(\%)\end{array}$ & $\begin{array}{l}12 \text { months postop } \\
n(\%)\end{array}$ \\
\hline \multicolumn{4}{|l|}{ Mobility } \\
\hline No problems in walking about & $6462(62.6)$ & $2039(19.7)$ & $3203(31.0)$ \\
\hline Some problems in walking about & $3750(36.3)$ & $7991(77.4)$ & $6795(65.8)$ \\
\hline Confined to bed & $113(1.1)$ & $295(2.9)$ & $327(3.2)$ \\
\hline \multicolumn{4}{|l|}{ Self-care } \\
\hline No problems with self-care & $8013(77.6)$ & $5434(52.6)$ & $6120(59.3)$ \\
\hline Some problems with self-care & $1866(18.1)$ & $2882(37.6$ & $3246(31.4)$ \\
\hline Unable to wash or dress & $446(4.1)$ & $1009(9.8)$ & $959(9.3)$ \\
\hline \multicolumn{4}{|l|}{ Usual activities } \\
\hline No problems in performing usual activities & $6217(60.2)$ & $2619(25.4)$ & $3418(33.1)$ \\
\hline Some problems in performing usual activities & $3098(30.0)$ & $5604(54.3)$ & $4880(47.3)$ \\
\hline Unable to perform usual activities & $1010(9.8)$ & $2102(20.4)$ & 2027 (19.6) \\
\hline \multicolumn{4}{|l|}{ Pain/discomfort } \\
\hline No pain or discomfort & $6446(62.4)$ & $2612(25.3)$ & $3534(34.2)$ \\
\hline Some pain or discomfort & $3354(32.5)$ & $6779(65.7)$ & $6065(58.7)$ \\
\hline Extreme pain or discomfot & $525(5.1)$ & $934(9.0)$ & $726(7.0)$ \\
\hline \multicolumn{4}{|l|}{ Anxiety/depression } \\
\hline Not anxious or depressed & $7636(74.0)$ & $6476(62.7)$ & $6549(63.4)$ \\
\hline Moderately anxious or depressed & $2412(23.4)$ & $3406(33.0)$ & $3411(33.0)$ \\
\hline Exteremely anxious or depressed & $277(2.7)$ & $443(4.3)$ & $365(3.5)$ \\
\hline
\end{tabular}

\section{PROM data according to fracture type}

The quality of life by the EQ-5D proportions for the different fracture types is presented in Additional file 1. The patients operated due to trochanteric fractures reported statistically significant more problems preoperatively than the other fracture types. The patients operated due to a FFN reported statistically significant lesser problems at all follow-ups compared to other fracture types. Regarding anxiety and depression the differences were less evident, but still better results were reported for the FFNs. The changes in severity level from preoperative to the four months follow up for each of the dimensions of the EQ-5D and for each fracture type are shown in Fig. 2. More than half of the patients with FFN reported no changes in the severity level of each dimension at four months postoperatively compared to their preoperative quality of life. Compared to patients with FFN, a higher proportion of patients with trochanteric and in particular subtrochanteric fractures reported increased problems in all dimensions at four months postoperative. For all fracture types only a small proportion of patients reported less problems four months postoperative compared to their preoperative functional level.

Figure 3 shows the mean VAS pain from the operated hip at the two postoperative follow-ups. Differences in mean pain between the different fracture types were found at all follow-ups; i.e. patients operated for a FFN reported the lowest pain at all follow-ups compared to trochanteric and subtrochanteric fractures. For all fracture types the mean pain decreased over time. However, the mean pain after 12 months was still between 22 and 28 , indicating that pain from the operated hip still may be an issue for at least some of the patients.

\section{PROM data according to age}

The youngest age group ( $<70$ years) reported the best quality of life in all dimensions except pain/discomfort at all follow-ups compared to the older age groups [see Additional file 2]. However, even in the youngest patient group problems in all dimensions were frequent following hip fractures. After twelve months more than $56 \%$ of the youngest patients had problems in walking, $23 \%$ had problems with self-care, and $51 \%$ had problems performing usual activities. The oldest age group ( $>80$ years) reported problems most frequently. The differences between the age groups were statistically significant in all dimensions and at all follow-ups.

\section{Discussion}

To our knowledge this is the first study presenting complete descriptive EQ-5D health profiles for a large 
Table 3 Descriptive profile of the 5 dimensions of EQ-5D after hip fracture. Sub-analyses including only patients reporting no problems preoperatively

\begin{tabular}{|c|c|c|}
\hline & $\begin{array}{l}4 \text { months } \\
\text { postop } \\
n(\%)\end{array}$ & $\begin{array}{l}12 \text { months } \\
\text { postop } \\
n(\%)\end{array}$ \\
\hline \multicolumn{3}{|l|}{ Mobility $(n=6462)$} \\
\hline No problems in walking about & $1858(28.8)$ & $2699(41.8)$ \\
\hline Some problems in walking about & $4544(70.3)$ & $3702(57.3)$ \\
\hline Confined to bed & $60(0.9)$ & $61(0.9)$ \\
\hline \multicolumn{3}{|l|}{ Self-care $(n=8013)$} \\
\hline No problems with self-care & $5197(64.9)$ & $5696(71.1)$ \\
\hline Some problems with self-care & $2601(32.5)$ & $2097(26.2)$ \\
\hline Unable to wash or dress & $215(2.7)$ & $220(2.7)$ \\
\hline \multicolumn{3}{|l|}{ Usual activities $(n=6217)$} \\
\hline No problems in performing usual activities & $2430(39.1)$ & $2953(47.5)$ \\
\hline Some problems in performing usual activities & $3309(53.2)$ & $2831(45.5)$ \\
\hline Unable to perform usual activities & $478(7.7)$ & $433(7.0)$ \\
\hline \multicolumn{3}{|l|}{ Pain/discomfort $(n=6446)$} \\
\hline No pain or discomfort & $2252(34.9)$ & $2650(41.1)$ \\
\hline Some pain or discomfort & 3845 (59.6) & $3507(54.4)$ \\
\hline Extreme pain or discomfot & $349(5.4)$ & $289(4.5)$ \\
\hline \multicolumn{3}{|l|}{ Anxiety/depression ( $n=7636)$} \\
\hline Not anxious or depressed & $6197(81.2)$ & $5852(76.6)$ \\
\hline Moderately anxious or depressed & $1366(17.9)$ & $1691(22.1)$ \\
\hline Exteremely anxious or depressed & $73(1.0)$ & $93(1.2)$ \\
\hline
\end{tabular}

For each dimension, only patients who reported «no problem» preoperatively are included

group of patients with hip fractures on a national level. The quality of life according to the EQ-5D was considerable reduced after a hip fracture and the deterioration sustained the first year postoperatively. The changes in EQ-5D were present in all age groups and for all types of fracture. The most interesting finding was, however, that also a lot of patients reporting no preoperative problems in walking, with self-care, and in performing usual activities experienced the same deterioration in function.

The deterioration in quality of life after hip fractures found in the present article is in good accordance with earlier results from both randomized trials and prospective studies $[1-3,5,24-26]$. Most studies reporting quality of life results have used the EQ-5D index score. As these scores can be based on different tariffs, with adjustments for cultural and national differences, the values presented in different studies may not be directly comparable.

The patients with femoral neck fractures reported less problems, higher quality of life, and lower average pain from the operated hip at all follow-ups compared to those with trochanteric or with subtrochanteric fractures. In Norway, there has been a change from closed reduction and internal fixation towards extensive use of hemiarthroplasties in the treatment of displaced femoral neck fractures [6]. Hemiarthroplasties have in earlier studies been found to result in fewer reoperations and provide better functional results than internal fixation for femoral neck fractures [1, 2, 27]. Accordingly, treatment with hemiarthroplasty is probably one reason to the good PROM outcomes for the femoral neck fractures in the present study. Patients with trochanteric fractures reported more problems and pain preoperatively compared to the other fracture types. The reason for this is unclear. However, one contributing factor can be that patients with trochanteric fractures earlier have been found to be older than patients with other fracture types [21, 28].

One interesting finding in this study was that a surprisingly high proportion of the patients reported no changes in the severity levels of EQ-5D-3L at four months postoperatively compared to their preoperative levels. These results probably illustrate one important limitation of the EQ-5D-3L. With only three severity levels the discriminatory power may be too low. When 


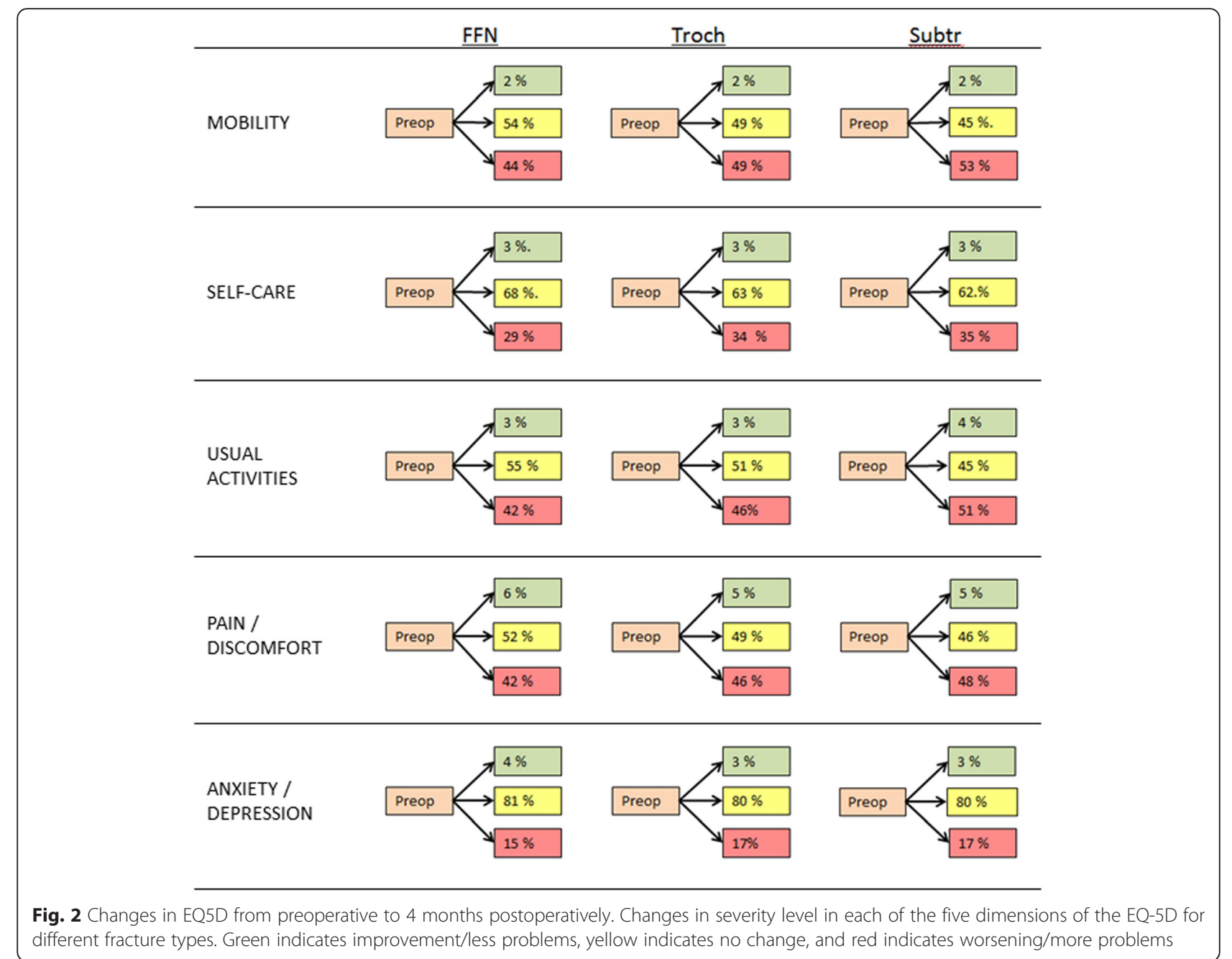

Fig. 2 Changes in EQ5D from preoperative to 4 months postoperatively. Changes in severity level in each of the five dimensions of the EQ-5D for different fracture types. Green indicates improvement/less problems, yellow indicates no change, and red indicates worsening/more problems

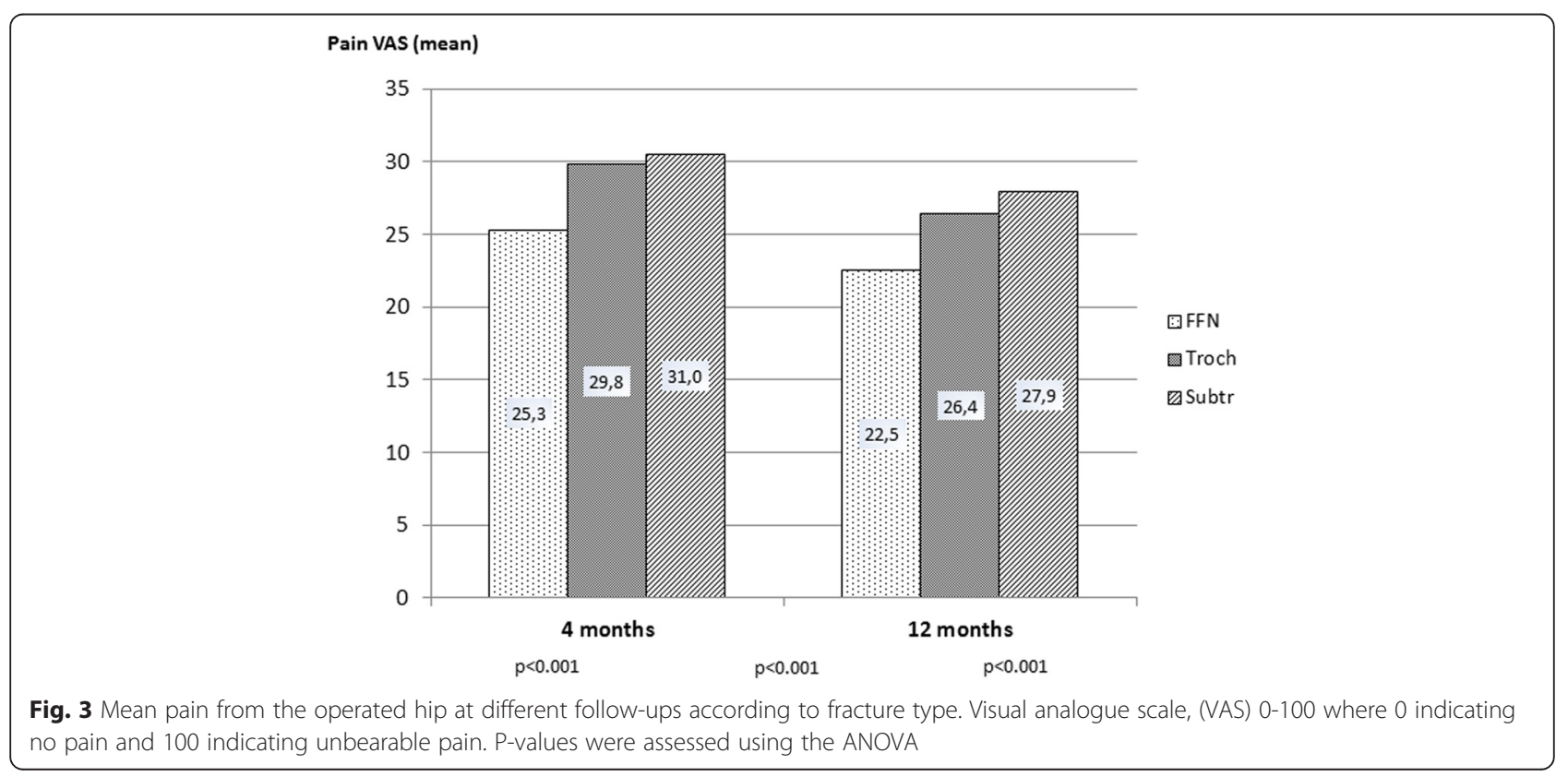


analyzing the results of hip fracture patients, one should have in mind that a high proportion of these patients have a reduced walking ability, have problems with selfcare and in performing usual activities, and are suffering from pain or discomfort already before the hip fracture. Consequently, the EQ-5D-3L instrument may have problems in detecting further deterioration in quality of life.

\section{Strength and limitations}

The strengths of our results are the high number of patients and that we present nation-wide results. The response rates of the 4 and the 12 months questionnaires were approximately $50 \%$ for the living patients, and the response rate of patients answering both questionnaires was only $34 \%$. The reason for this low response rate is probably high age and high degree of comorbidity among the patients. Reminders could probably have improved the response rate. The study population represented a selected group of patients as they have all survived the first 12 months after surgery and answered the 12 months questionnaire. The results showed that they were younger and healthier than the non-responders. This is also verified when comparing the baseline characteristics of patients in the present study with earlier studies from the Norwegian Hip Fracture Register, which has reported on older and more comorbid patients [2, 29-33]. Accordingly, one major limitation of the present study is the risk for selection bias. Thus, the results reported in this study may be a best-case scenario excluding the oldest and most comorbid patients with the expected worst quality of life. However, even if a selection bias exists, the absolute number of patients reporting problems following hip fractures was still high.

One other limitation of the study is that it was not a randomized trial and, accordingly, no matched control group. We cannot conclude that all the changes in quality of life over time were caused by the hip fracture itself. To some extent these changes were probably part of the natural life course for these old and frail patients irrespective of the fracture. The EQ-5D index score has been thoroughly validated in several studies including elderly hip fracture patients [34-38]. As far as we know, similar validation of the EQ-5D health profiles has not been done. However, the use of EQ-5D health profiles as used in the present study is one of the recommended methods to present quality of life results according to the EuroQol group [39]. Finally, a recall bias may exist as the preoperative EQ$5 \mathrm{D}$ data was retrospectively recorded four months after surgery. Two studies have found moderate or good correlation when comparing recalled data and prospective data in outcome studies after arthroplasties [40, 41].
Consequently we believe we largely can trust the recalled preoperative data.

\section{Conclusions}

A hip fracture has a dramatic impact on the patients' HRQoL, also for patients with no health-related problems preoperatively. The deterioration in HRQoL sustained also twelve months after the fracture. The use of the descriptive profile of the EQ-5D is useful when assessing quality of life after hip fracture surgery.

\section{Additional files}

Additional file 1: Descriptive profile of the 5 dimensions of the EQ-5D - different hip fractures. Description of data: Preoperative and postoperative distribution of the descriptive profile of the EQ-5D according to fracture type and length of follow-up. All patients included. (DOCX $18 \mathrm{~kb}$ )

Additional file 2: Descriptive profile of the 5 dimensions of the EQ-5D - different age groups. Description of data: Preoperative and postoperative distribution of the descriptive profile of the EQ-5D according to age group and length of follow-up. All patients included. (DOCX $21 \mathrm{~kb}$ )

\section{Abbreviations}

VAS, visual analalogue scale; HRQoL, health related quality of life; EQ-5D, EuroQol - 5 dimensions questionnaire; PROM, patient reported outcome measures; NHFR, Norwegian Hip Fracture Register; FFN, fracture of femoral neck; ASA, American Society of Anaesthesiologists.

\section{Acknowledgements}

The authors thank all Norwegian orthopedic surgeons who have loyally reported to the Norwegian Hip Fracture Register.

\section{Funding}

The Helse-Vest RHF Regional Health Board funds the Norwegian Hip Fracture Register.

\section{Availability of data and materials}

Due to regulations from the Norwegian Data Inspectorate and according to Norwegian personal protection laws publication of the complete dataset is not legal or appropriate.

\section{Authors' contributions}

All authors, JEG, VB, JMF, OF and LBE, participated in the design of the study, in interpretation of the results, in elaboration of the manuscript, and approved the final draft. JEG and VB performed the statistical analyses. JEG wrote the manuscript. All authors read and approved the final manuscript.

\section{Competing interests}

The authors declare that they have no competing interests.

\section{Consent for publication}

Not applicable.

\section{Ethics approval and consent to participate}

The Norwegian Data Inspectorate has approved the registration in the NHFR. Since no additional information was collected in the present study, an approval from an ethics committee was not necessary.

Received: 4 February 2016 Accepted: 2 June 2016

Published online: 07 July 2016

\section{References}

1. Frihagen F, Nordsletten L, Madsen JE. Hemiarthroplasty or internal fixation for intracapsular displaced femoral neck fractures: randomised controlled trial. BMJ. 2007;335(7632):1251-4. 
2. Gjertsen JE, Vinje T, Engesaeter LB, Lie SA, Havelin LI, Furnes O, Fevang JM. Internal screw fixation compared with bipolar hemiarthroplasty for treatment of displaced femoral neck fractures in elderly patients. J Bone Joint Surg Am. 2010;92-A(3):619-28.

3. Keating JF, Grant A, Masson M, Scott NW, Forbes JF. Randomized comparison of reduction and fixation, bipolar hemiarthroplasty, and total hip arthroplasty. Treatment of displaced intracapsular hip fractures in healthy older patients. J Bone Joint Surg Am. 2006:88(2):249-60.

4. Roden M, Schon M, Fredin H. Treatment of displaced femoral neck fractures: a randomized minimum 5-year follow-up study of screws and bipolar hemiprostheses in 100 patients. Acta Orthop Scand. 2003;74(1):42-4

5. Rogmark C, Carlsson A, Johnell O, Sernbo I. A prospective randomised trial of internal fixation versus arthroplasty for displaced fractures of the neck of the femur. Functional outcome for 450 patients at two years. J Bone Joint Surg (Br). 2002;84(2):183-8.

6. Havelin LI, Furnes O, Engesaeter LB, Fenstad AM, Dybvik E. The Norwegian Arthroplasty Register. Annual report 2014. ISBN: 978-82-91847-19-1 ISSN: 1893-8914. 2014

7. Rogmark C, Spetz CL, Garellick G. More intramedullary nails and arthroplasties for treatment of hip fractures in Sweden. Acta Orthop. 2010;81 (5):588-92.

8. Blomfeldt R, Tornkvist H, Ponzer S, Soderqvist A, Tidermark J. Internal fixation versus hemiarthroplasty for displaced fractures of the femoral neck in elderly patients with severe cognitive impairment. J Bone Joint Surg (Br). 2005;87(4):523-9.

9. Leonardsson O, Rolfson O, Hommel A, Garellick G, Akesson K, Rogmark C. Patient-reported outcome after displaced femoral neck fracture: a national survey of 4467 patients. J Bone Joint Surg Am. 2013;95(18):1693-9.

10. Osnes EK, Lofthus CM, Meyer HE, Falch JA, Nordsletten L, Cappelen I, Kristiansen IS. Consequences of hip fracture on activities of daily life and residential needs. Osteoporos Int. 2004;15(7):567-74.

11. Ayers DC, Bozic KJ. The importance of outcome measurement in orthopaedics. Clin Orthop Relat Res. 2013;471(11):3409-11.

12. Franklin PD, Harrold L, Ayers DC. Incorporating patient-reported outcomes in total joint arthroplasty registries: challenges and opportunities. Clin Orthop Relat Res. 2013;471(11):3482-8.

13. Blomfeldt R, Tornkvist H, Ponzer S, Soderqvist A, Tidermark J. Displaced femoral neck fracture: comparison of primary total hip replacement with secondary replacement after failed internal fixation: a 2-year follow-up of 84 patients. Acta Orthop. 2006;77(4):638-43.

14. Enocson A, Pettersson H, Ponzer S, Tornkvist H, Dalen N, Tidermark J. Quality of life after dislocation of hip arthroplasty: a prospective cohort study on 319 patients with femoral neck fractures with a one-year follow-up. Qual Life Res. 2009:18(9):1177-84.

15. Figved W, Opland V, Frihagen F, Jervidalo T, Madsen JE, Nordsletten L. Cemented versus uncemented hemiarthroplasty for displaced femoral neck fractures. Clin Orthop Relat Res. 2009;467(9):2426-35.

16. Hedbeck CJ, Blomfeldt R, Lapidus G, Tornkvist H, Ponzer S, Tidermark J. Unipolar hemiarthroplasty versus bipolar hemiarthroplasty in the most elderly patients with displaced femoral neck fractures: a randomised, controlled trial. Int Orthop. 2011;35(11):1703-11.

17. Tidermark J, Ponzer S, Svensson O, Soderqvist A, Tornkvist H. Internal fixation compared with total hip replacement for displaced femoral neck fractures in the elderly. A randomised, controlled trial. J Bone Joint Surg (Br). 2003:85(3):380-8.

18. Jansson KA, Nemeth $G$, Granath F, Jonsson B, Blomqvist P. Health-related quality of life (EQ-5D) before and one year after surgery for lumbar spinal stenosis. J Bone Joint Surg (Br). 2009;91(2):210-6.

19. Ostendorf M, van Stel HF, Buskens E, Schrijvers AJ, Marting LN, Verbout AJ, Dhert WJ. Patient-reported outcome in total hip replacement. A comparison of five instruments of health status. J Bone Joint Surg (Br). 2004;86(6):801-8.

20. Rolfson O, Karrholm J, Dahlberg LE, Garellick G. Patient-reported outcomes in the Swedish Hip Arthroplasty Register: results of a nationwide prospective observational study. J Bone Joint Surg (Br). 2011;93(7):867-75.

21. Gjertsen JE, Engesaeter LB, Furnes O, Havelin LI, Steindal K, Vinje T, Fevang $J M$. The Norwegian Hip Fracture Register. Experiences after the first 2 years and 15,576 reported hips. Acta Orthop. 2008;79(5):583-93.

22. American Society of Anaesthesiologists. New classification of physical status. Anaesthesiology. 1963;24:111.

23. Brooks R. EuroQol: the current state of play. Health Policy. 1996;37(1):53-72.
24. Blomfeldt R, Tornkvist H, Ponzer S, Soderqvist A, Tidermark J. Comparison of internal fixation with total hip replacement for displaced femoral neck fractures. Randomized, controlled trial performed at four years. J Bone Joint Surg Am. 2005;87(8):1680-8.

25. Ravikumar KJ, Marsh G. Internal fixation versus hemiarthroplasty versus total hip arthroplasty for displaced subcapital fractures of femur-13 year results of a prospective randomised study. Injury. 2000;31(10):793-7.

26. Stoen RO, Lofthus CM, Nordsletten L, Madsen JE, Frihagen F. Randomized trial of hemiarthroplasty versus internal fixation for femoral neck fractures: no differences at 6 years. Clin Orthop Relat Res. 2014;472(1):360-7.

27. Parker MJ, Khan RJ, Crawford J, Pryor GA. Hemiarthroplasty versus internal fixation for displaced intracapsular hip fractures in the elderly. A randomised trial of 455 patients. J Bone Joint Surg (Br). 2002;84(8):1150-5.

28. Cornwall R, Gilbert MS, Koval KJ, Strauss E, Siu AL. Functional outcomes and mortality vary among different types of hip fractures: a function of patient characteristics. Clin Orthop Relat Res. 2004;425:64-71.

29. Gjertsen JE, Fevang JM, Matre K, Vinje T, Engesaeter LB. Clinical outcome after undisplaced femoral neck fractures. Acta Orthop. 2011;82(3):268-74.

30. Gjertsen JE, Lie SA, Vinje T, Engesaeter LB, Hallan G, Matre K, Furnes O. More reoperations with uncemented hemiarthroplasties than with cemented hemiarthroplasties for the treatment of displaced femoral neck fractures. An observational study of 11116 hemiarthroplasties reported to the Norwegian Hip Fracture Register. JBJS Br. 2012;94(8):1113-9.

31. Matre K, Havelin LI, Gjertsen JE, Espehaug B, Fevang JM. Intramedullary nails result in more reoperations than sliding hip screws in two-part intertrochanteric fractures. Clin Orthop Relat Res. 2013:471(4):1379-86.

32. Matre K, Havelin LI, Gjertsen JE, Vinje T, Espehaug B, Fevang JM. Sliding hip screw versus IM nail in reverse oblique trochanteric and subtrochanteric fractures. A study of 2716 patients in the Norwegian Hip Fracture Register. Injury. 2013;44(6):735-42

33. Talsnes O, Vinje T, Gjertsen JE, Dahl OE, Engesaeter LB, Baste V, Pripp AH, Reikeras O. Perioperative mortality in hip fracture patients treated with cemented and uncemented hemiprosthesis: a register study of 11,210 patients. Int Orthop. 2013;37(6):1135-40.

34. Tidermark J, Zethraeus N, Svensson O, Tornkvist H, Ponzer S. Femoral neck fractures in the elderly: functional outcome and quality of life according to EuroQol. Qual Life Res. 2002:11(5):473-81.

35. Tidermark J, Bergstrom G. Responsiveness of the EuroQol (EQ-5D) and the Nottingham Health Profile (NHP) in elderly patients with femoral neck fractures. Qual Life Res. 2007;16(2):321-30.

36. Coast J, Peters TJ, Richards SH, Gunnell DJ. Use of the EuroQoL among elderly acute care patients. Qual Life Res. 1998;7(1):1-10.

37. Frihagen F, Grotle M, Madsen JE, Wyller TB, Mowinckel P, Nordsletten L. Outcome after femoral neck fractures: a comparison of Harris Hip Score, Eq-5d and Barthel Index. Injury. 2008;39(10):1147-56.

38. Tidermark J, Bergstrom G, Svensson O, Tornkvist H, Ponzer S. Responsiveness of the EuroQol (EQ 5-D) and the SF-36 in elderly patients with displaced femoral neck fractures. Qual Life Res. 2003:12(8):1069-79.

39. EQ-5D-3L User Guide. Version 4.0. EuroQol group 2011.

40. Howell J, Xu M, Duncan CP, Masri BA, Garbuz DS. A comparison between patient recall and concurrent measurement of preoperative quality of life outcome in total hip arthroplasty. J Arthroplasty. 2008;23(6):843-9.

41. Lingard EA, Wright EA, Sledge CB. Pitfalls of using patient recall to derive preoperative status in outcome studies of total knee arthroplasty. J Bone Joint Surg Am. 2001;83-A(8):1149-56. 2008.

\section{Submit your next manuscript to BioMed Central and we will help you at every step:}

- We accept pre-submission inquiries

- Our selector tool helps you to find the most relevant journal

- We provide round the clock customer support

- Convenient online submission

- Thorough peer review

- Inclusion in PubMed and all major indexing services

- Maximum visibility for your research

Submit your manuscript at www.biomedcentral.com/submit 